\title{
Localization and the Chinese Overseas: Acculturation, Assimilation, Hybridization, Creolization, and Identification
}

\author{
TAN Chee-Beng \\ Sun Yat-sen University, Guangzhou, China
}

\begin{abstract}
Based on materials on the localized Chinese overseas, including the Melaka Babas, who are mostly Malay-speaking Chinese, this article reflects on the use of such terms as acculturation and assimilation, as well as hybridization and creolization, in relation to highly localized Chinese. All these concepts are seen as different ways of describing cultural formation in transcultural context. In particular, the relevance of using creolization to refer to the kind of creative process of cultural formation beyond its original usage in the Caribbean is discussed. This results in the identification of fragmented creolization as in the case of the Caribbean and a rooted creolization as in the case of the Babas. The author shall first discuss the issues of assimilation and integration, followed by hybridization and creolization. This is followed by the discussion on localization of Chinese overseas and identity. The concluding section provides some remarks on the concepts reviewed, and three main categories of acculturated Chinese are identified, namely, Chinese who are linguistically assimilated but still observe major Chinese traditions, Chinese who are so acculturated to the mainstream society that they hardly practice Chinese traditions, and Chinese who are both highly localized and highly mixed "racially".
\end{abstract}

Keywords: acculturation and assimilation, hybridization, creolization, localization and identity, Baba, Chinese overseas

\section{Introduction $^{1}$}

A noticeable feature of Chinese overseas is their local cultural adaptation. In a number of cases, certain cultural features are so localized and similar to the local people that the Chinese are perceived and even described as assimilated. Common examples of these can be found in Malaysia, Indonesia, and Thailand; indeed throughout Southeast Asia, and in North and South America as well as in parts of Africa. Some of them, such as the "Baba" in Malaysia and Singapore and other so-called creolized Chinese communities, are so acculturated that they are considered as either "assimilated" or not quite Chinese. As I have seen in the case of the Baba, the tendency to emphasize the "assimilated" aspects is misleading, as the identity of the Baba, for instance, needs to be understood in the context of both acculturation and Chinese cultural persistence. Malay-like cultural features can be over emphasized to show that the Babas are Malay-like and un-Chinese, but traditional Chinese cultural features, such as Chinese ancestor worship or Chinese symbolism, can be

Tan Chee-Beng, Ph.D., Distinguished Professor, Department of Anthropology, Sun Yat-sen University.

${ }^{1}$ A version of this paper was presented at the Workshop on Chinese Diasporas and Autchtonous Identities held at the University of French Polynesia, Tahiti, on 10-11 September 2015. It was revised and translated into French and published as Tan Chee-Beng, "Les Chinois d'outre-mer et les phénoménes de créolisation,” in Diasporas chinoises et créolisations, eds., Emmanuel Ma Mung, Léopold Mu Si Yan, and Bruno Saura, Paris: Editions You Feng Libraire \& Editions, 2016. The revised English paper is published here for the first time. 
highlighted by the Babas to show that they are culturally very Chinese. Only a unity of such differentiated perspectives can enlighten us about the nature of Baba cultural life and their identity, as I have sought to illustrate in my book (Tan, 1988).

The Malay-speaking Chinese called "Baba" in Malaysia and Singapore ${ }^{2}$ have been described by some scholars as hybridized and creolized (e.g., Chua \& Ananda, 2001), or creolized and intermediate (Skinner, 1996), and they are perceived by many people in Malaysia as somewhat "assimilated" by the Malays. Since my intensive anthropological research among the Babas in Melaka in 1977, I have observed the community over the years. I have tried to show in my writings that the Melaka Babas have remained a distinct category of Chinese despite speaking Malay and English among themselves. In this article, I wish to review the use of such terms as acculturation and assimilation, as well as hybridization and creolization, in relation to the Babas and other highly localized Chinese. All these concepts are seen as different ways of describing cultural formation arising from groups in contact, although post-colonial scholars relate the terms hybridization and creolization more generally to globalization. I shall first discuss the issues of assimilation and integration, followed by hybridization and creolization. I shall then discuss the localization of Chinese overseas and identity. In the conclusion, I shall identify three main categories of acculturated Chinese as well as give some final remarks on the concepts reviewed.

In addition, I have used the concept of "localization" which I have defined as the process of cultural adjustment to a local geographical and social environment and identifying with the locality (Tan, 2004, 23). This is a more general concept which results in various features of acculturation. Globalization theorists use localization to refer to the process of transforming the global local; my usage of localization is more general, being a process of culturally becoming local without necessarily contrasted with globalization. In fact, all migrant cultural features involve localization as they are practiced in a particular locality. To emphasize the cultural dimension, I shall also use the term "cultural localization".

\section{Assimilation and Integration}

Anthropologists usually make a distinction between acculturation and assimilation, although nowadays they seem to have shied away from such terms, perhaps for fear of being accused of seeing people as passively being changed. In actual fact, one need not and should not see a person as being passively acculturated by another ethnic group in contact. Individuals living in a particular cultural context actively make choices to adapt to living in a particular environment. As a contrast to the phenomenon of people merging into another ethnic category, acculturation remains a useful concept. While many scholars have defined acculturation and assimilation, that of Teske and Nelson (1974) remains the clearest. These concepts are best understood in the context of people in direct contact, and acculturation involves cultural change in the direction of the group or groups in contact, while assimilation involves a change in reference group. This process of cultural transformation is not a one-direction unitary process, and acculturation does not necessarily lead to assimilation. A contribution of my Baba study is to illustrate that people can be so acculturated and still remain ethnically distinct, that is, in the case of the Babas, they remain Chinese, albeit a different kind of Chinese.

Some scholars and lay people often assume that a high level of acculturation will lead to assimilation. Leaving aside the issue of definition, such a view is often linked to an essentialist view of identity, Chineseness

\footnotetext{
${ }^{2}$ For some studies on the Babas, see Clammer (1980), Tan (1988), Rudolph (1998), and Chia (2010).
} 
in the case of the study of the Chinese overseas. This is particularly so with the perception that losing the language associated with an ethnic category results in assimilation. The Baba example is useful to show that such a view is misleading. The Melaka Babas continue to remain Chinese even though few of them can speak any Chinese language. Losing the Chinese mother tongue does not necessarily result in ethnic assimilation. However, it does affect the nature of the cultural expression of a Chinese identity: Babas see themselves and are perceived by other Chinese as a different kind of Chinese. The Baba identity is a local Chinese identity that need not be qualified when contrasting with the mainstream non-Baba Chinese, and it is not a contradiction or denial of identity when a Baba emphasizes that he or she is a Baba and describes the non-Baba Chinese as Cina or "Chinese". As I have pointed out, the assimilationists generally emphasize the acculturated or "assimilated" features and ignore cultural features that are less or not acculturated.

Many scholars, especially those outside the discipline of anthropology, generally do not make this kind of clear distinction between acculturation and assimilation, and both phenomena are described as assimilation. This may be convenient but can be confusing when scholars debate whether the Chinese in Thailand are assimilated or not. The so-called assimilation model of Skinner $(1957 ; 1960)$ in the study of the Chinese in Southeast Asia, Thailand in particular, has been debated (Hill, 1998; Tong \& Chan, 2001), but a very core issue is really Skinner's usage of "assimilation”. He uses "assimilation” in two ways: (1) the Chinese have become more like the Thai, such as speaking Thai, and (2) the Chinese have become Thais and ceased to be Chinese. Most of the time, he refers to the former but assumes the latter. We should, however, note that Professor Skinner wrote at a time before the modern anthropological scholarship on ethnicity, which emphasizes the social constructionist model (Jenkins, 1997, 17), and he sought to show that the "overseas Chinese" could "assimilate" (read integrate) into a host society.

There is thus the issue of assimilation and integration. Just like a high level of acculturation does not necessarily lead to assimilation, more acculturation does not necessarily mean more integration into a larger society. Acculturation and assimilation are cultural processes albeit influenced by political factors, but integration is the political process of becoming part of a larger society; and it can foster more acculturation. Wong (1978) argues that discriminatory policies against the Chinese in U.S.A. did not encourage their "assimilation". The term assimilation here really means integration and acculturation, i.e., less discriminatory policies encourage integration and subsequently more acculturation. A policy of political assimilation, as in Indonesia under President Suharto, may bring about more acculturation but not necessarily integration. Integration requires acceptance on the part of the mainstream society and its government. As long as a minority is treated as somewhat alien and is not accepted as equal citizens, its members cannot be fully integrated, no matter how much they are acculturated towards the mainstream society. Expectation of full assimilation to a particular cultural or ethnic model also makes integration impossible. There cannot be an essentialist view of being American or Indonesian, as each individual can have different imagination and cultural expression of being American or Indonesian. Furthermore, integration should not be equated with assimilation to a particular ethnic group. Some governments may insist on minorities assimilating into the majority category, but this violates human rights. There is a need for a definition that emphasizes opportunities for participation in the mainstream society on the part of the minorities, as I have defined in Tan (1994, 241). If opportunities to participate are restricted, there cannot be meaningful integration. On the other hand, where there is equal opportunity for minorities to participate in the national society, integration can be achieved, and as a result, minorities may be even more culturally localized. 


\section{Hybridity and Creolization}

The popular image of the Babas in Malaysia is that they are racially and culturally mixed, and mainstream Chinese consider them as not pure, not quite Chinese. Scholars influenced by post-colonial scholarship find the Babas a convenient example to apply the hybridity theory. I find all these misleading. While the early Chinese settlers had intermarried with non-Chinese, a common phenomenon in early Chinese migration when there was a lack of Chinese women, the Babas had been marrying their own women and non-Baba Chinese with the arrival and presence of more Chinese immigrants. Today they generally marry among the Chinese, as do most mainstream Chinese. It is thus misleading to describe the Babas as a mere product of intermarriage or mixed-blood between Malays and Chinese. The term "hybrid" originally means mixing different breeds of animals and today post-colonial studies scholars generally use it to refer to cultural mixing, to emphasize cultural fluidity and that no culture is pure, and to avoid essentializing culture.

The scholar who has the most influence on such post-colonial theorizing is Bhabha (1994). While it seems right to point out that all cultures are "hybrid", by the 1980s when post-colonial writing became popular, anthropologists have already held the view that there is no pure culture, that all cultural formation is influenced by different forms of cultural influences. With this understanding, there is no need to say that all cultures are hybrid, only that some are more "hybrid" than others. The problem is that hybridity gives the idea of being mixed between categories whereas cultural formation really involves creation either by incorporating other cultural influences into existing meaningful cultural life or creating something altogether new; this later process may be called creolization (see below). For lack of a term, this negotiation and incorporation process in cultural formation, or culture-building according to Mintz (1998, 119), may be described as in-culturalizing. In interaction between cultures, a people usually in-culturalize "alien" cultural influences into their familiar cultural complex, only when the influence or discrimination of the larger society is so dominant that individuals may choose to acculturate directly to the cultural forms of the dominant society. When groups in contact mutually in-culturalize each other's cultural life styles, this may be called inter-culturalizing. Mintz $(1998,119)$ reminds us that Ortiz (1947) had invented the term "transculturation". I find the adjective "transcultural" useful to refer to the context of interaction between cultures. However, I wish to distinguish between the transcultural cultural formation within a group, and different groups mutually involve in similar transcultural culture-building.

To describe Baba culture as hybrid is misleading in that it gives the image that it is overall culturally mixed. Cultural formation is an innovative process that involves selection and incorporation as well as reinvention to adjust to a cultural style and it is misleading to emphasize the process as mere mixing. While hybridity scholars emphasize mixing as innovation, the image of hybridity as mixed or blended between categories is inescapable. Hybridity really tells us nothing much and scholars may even misuse the concept to theorize that, for instance, all Baba cultural features are mixed between Malay and Chinese cultural styles; in actual fact, the cultural formation is more complex than this, as we have seen. Theorizing hybridity often essentializes hybridity by assuming overall mixing between categories. Given that hybridity is also linked to racial mixing, the theorizing of Baba cultural life as hybrid only reinforces the popular misconception, and legitimizes the prejudice against the Baba as not really Chinese. While the original intention of theorizing hybridity is to emphasize that cultures are all hybrid, its use actually stirs up an image of contrasting with a pure status, which is of course non-existing. Bhabha's abstract idea of third space articulation of cultural difference (Bhabha, 1994, 36; Childs \& Williams, 1997, 142) does not help either, since people perceive and 
practice social categorization even when scholars choose to deny its existence by highlighting hybridity and cultural fluidity.

Indeed I feel uncomfortable to use the term hybridity to refer to the Babas, even though it is theoretically convenient and appears "sophisticated". My work has been to counteract the mainstream Chinese perception of the Baba as "not pure" or "corrupted", that marginalizes them to a culturally degraded Chinese community. Nor can the Baba cultural heritage or community be conceived as "intermediate" between Malays and Chinese. As localized Chinese, the Babas have incorporated Malaysian cultural features in distinctive integrated forms that are not mere mixing between Chinese and Malays but are distinctively Baba. It is like integrative knowledge that grows out of various familiar forms of knowledge. Thus, the popular image of Baba "culture" as mixed between Malays and Chinese is misleading. The term "intermediate community" is inappropriate precisely because it reinforces this image of being mixed between two pure categories. Skinner (1996) probably uses the term "intermediate" as a convenient term to connote an intermediate status between the colonial power and the local communities. This is of course a loose usage. In the case of the Chinese Mestizo in the Philippines (Wickberg, 1964), they were by laws somewhat treated as "intermediate" between the whites and the natives and Chinese immigrants. In the case of the Babas, there was no legal recognition of "being intermediate" although in the 19th and early 20th centuries, the Europeans found it convenient to deal with the rich Babas as compradors, business middlemen between Europeans and the local. And the Babas, being local-born in the Straits Settlements, were British subjects, and were called Straits-born Chinese or Straits Chinese. The China-born Chinese were obviously not called Straits-born Chinese although some of them did become naturalized British subjects (Song, 1923, 69).

Now, can the Babas be described as creolized? Since the 1990s, a number of scholars on globalization have used creolization to describe, in the words of Mimi Scheller (2003, 273), "the ways in which cultural consumers throughout the world creatively adapt 'global' commodities, brands, and ideas to 'local' contexts". This is very different from its original usage to describe cultural contact and cultural creation in the Caribbean. Indeed, the word "creole" has been used in the Caribbean and Latin America since colonial time, initially applied to people of Spanish descent who were born and grew up in colonized South America. Later, the term referred to the Negro slaves in South America and today it refers to the blacks in general [Putnam (translator) in Freyre, 1986, 66; Menke \& França, 2005]. This changing usage is somewhat similar to the term Baba which was borrowed from the Middle East. It was originally used by the Malays to refer to local-born foreigners, later applied to offspring of union between foreigners and local people, and finally the term referred to local-born Chinese in the Straits Settlements in contrast to China-born immigrants (Tan, 1988, 12). Anyway, both the terms Creole and Baba connote local-born status. In fact, the Portuguese use of the word Creole (Crioulo) is derived from criar, which means "born or raised at home" (Van Lier, 1971, 2, Menke \& França, 2005). Creolization refers to the localization of whites in the Americas, and creoles were perceived by Europeans as inferior whites in the colony (Menke \& França, 2005). Eventually Creole was "often adapted and conceptualized as a product of Afro-European acculturation” (Menke \& França, 2005) ${ }^{3}$. It should be noted that the term Creole has a historical usage in the Americas and has to do with Europeans and non-Europeans, while

\footnotetext{
${ }^{3}$ I have learned much about the creoles in the Caribbean and South America from the workshop on "Mixing Races” organized by the University of Cape Town's Institute for Intercultural and Diversity Studies in South Africa, and the SEPHIS Program, held at the University of Cape Town, 16-21 June 2005. In particular, I wish to thank Jack Menke for his presentation "A Comparative Approach to 'Racial Mixing' in Latin America and the Caribbean: The Case of Brazil and Suriname”, which he jointly wrote with Maria Stela do Campos França.
} 
the concept of "Baba" is associated with the localization of the Chinese in the context of the Malay Archipelago, which first came under European colonization in 1511 (the fall of Melaka to the Portuguese). Furthermore, in the Caribbeans, creolization also refers to biological and cultural homogenization (Hoetink, 1973, 96).

Creolization as used in the Caribbean and Latin America is in fact a kind of localization process that is brought about by what Harney $(1996,94)$ calls cultural colonization, that involved migrants (such as Africans and Indians) acculturating in the direction of the colonial language and culture, giving rise to the European-based Creole which becomes the common language of the local people. This differs from the localization of the Babas who acculturated in the direction of the indigenous people although they had also incorporated some cultural elements of the colonial culture, and the creole language developed was a Malay-based creole. This is because there was a large indigenous population in Melaka, whereas in the Caribbean, for instance, the indigenous Indian population had almost disappeared. In fact, the most notable feature of creolization is language, the acquisition of a transculturated language of contact called creole. In Mauritius, for example, the French-based creole called Kreol is the language spoken by most Mauritians, including the localized Chinese (Eriksen, 1992, 96). While English is the official language in Jamaica and Trinidad \&Tobago, the popular local lingua franca is the English-based creole called Creole. The local-born Chinese speak Creole, too (Shibata, 2013, 365).

Thus, it is relevant to use creolization to refer to a process of creating something new out of inter-cultural interaction, as in the case of the creation of a creole language. Creolization can then be used to refer to the kind of significant transcultural formation that brings about a distinctive new cultural heritage, not just cultural transformation expressed within an existing cultural heritage. In the case of the Baba, we can identify two major cultural realms that are creolized, namely language and food. As we have seen, Baba Malay is a Malay Creole, and this is special as most creoles are formed out of the languages of Europeans and the colonized subjects. Baba Malay is formed out of early Chinese settlers using the Malay trade language in the Malay Archipelago, and during the colonial period, it was a respectable Malay language, although today the use of Standard Malay as the national language has marginalized the Baba Malay Creole to an illegitimate status. Some Baba parents told me that their children were told in school that Baba Malay (which has Hokkien loanwords) was wrong, and they asked why the Babas did not speak proper Malay.

Baba food, often called Nyonya food in association with the women (nyonya) who cook, is a well-known cuisine in Malaysia and Singapore, known for its spicy taste. It is often stereotyped as a mixed Malay and Chinese cuisine, but it is really a new cuisine that the Babas have created out of their knowledge of Chinese and local Malaysian and Singaporean (mainly Malay but including others such as that of the Portuguese) cuisines as well as their innovative use of local ingredients. The use of local ingredients or those not normally used in Chinese cuisine makes a nyonya dish distinct from a Chinese dish. Nyonya food really comprises modified Chinese and Malay-style dishes as well as innovatory dishes. It can thus be described as creolized. It has its own identity.

However, one cannot generalize that the whole Baba cultural heritage is creolized, for other than language and food and some visible features of dressing (mainly the older women wearing sarong and kebaya); other cultural features are really changing Chinese traditions or Chinese traditions expressed in Baba Malay language, such as performing ritual crying in Malay at a funeral. I say changing Chinese traditions to emphasize that traditions are not fixed and unchanging; in fact, they are modified by individuals in practice, due to acculturation or globalization or other practical convenience, but the traditions as a whole persist despite some 
transformation. Contrary to the imagery of assimilation, the symbolic world and cultural traditions of the Babas have remained Chinese. And if the "old-fashioned" Baba wedding is featured, it is perceived by the mainstream non-Baba Chinese as weird or out of date. The so-called Baba traditional wedding actually involves the practice of elaborate Chinese rituals and use of costumes of the Mandarin class in late imperial China. As far as we know, no other Chinese elsewhere in the world still marry in this "traditional" style. Thus, on the one hand, the Baba are portrayed by people as "assimilated" by the Malays, on the other hand, to use the traditional wedding as an essentialized feature, they are more Chinese than most Chinese! This reminds us of the need, as I have stressed, to see the Baba culturally as a whole and not just the acculturated features only.

Caribbean creolization has a long history, "beginning five centuries past” (Mintz, 1996, 301). As a localization process, creolization "had to do not just with the loss of culture, but also with some sort of indigenization", and culturally "they were busily becoming their own persons" (Mintz, 1996, 302). Indigenization and becoming a separate category of people are crucial features of creolization. It is thus reasonable to use the term creolization to loosely contrast a person that have a long history of localization and are more intensely acculturated to the local society with later migrants who are not so intensely acculturated. This is best indicated by the loss of one's original language and adoption of a local language or a creole language. It is in this sense that we can say the Malay-speaking Babas are creolized Chinese, a convenient way of saying that they are a more localized category of Chinese to the extent of speaking Malay instead of Chinese among themselves. But there is one important difference between Caribbean creolization and Baba creolization. In the case of the African slaves and their descendants in the Caribbean, they were brought there from different parts of Africa, and they were totally culturally uprooted despite sharing certain African rhythm of civilization. In the words of Mintz (1996, 302), "the creation and construction of culture out of fragmented, violent, and disjunct pasts” typified this kind of creolization. In the case of Babas, they originated from migrants from South China, mainly Southern Fujian, who brought with them their cultural traditions; only over the years they had lost their Chinese mother tongue and adopted a Malay creole as well as became indigenized in life style, but to this day they have retained many Chinese cultural traditions, perhaps more consciously so because of the loss of language. We can thus speak of two kinds of creolization, a fragmented creolization as in the case of the Caribbean and a rooted creolization as in the case of the Babas.

\section{Localization of Chinese Overseas and Identity}

A common feature of the Chinese overseas is the acquisition of the local languages, and depending on the history and circumstances of settlement, it is common to find ethnic Chinese who do not or hardly speak any Chinese language; instead, they speak only the dominant language of the region of residence. In fact, the ability to speak and identify with one or more local languages culturally distinguishes the Chinese of one nationality from that of another. This acquisition of the local languages is not surprising since linguistic adaptation is the first thing that migrants to a new cultural environment have to adjust to, so as to deal with the local people, to do business, or to earn a livelihood. Even early traders to the Malay Archipelago had to learn some Malay in order to trade. We know that in the 15th century, there already existed in China a list of Malay vocabulary written in Chinese characters, such as zhen jie 真皆 for cengkih (clove), na da 那答 lada (pepper), and ma gen na si 麻根那西 for makan nasi (eat rice) (Liang, 1996, 99-111).

In Indonesia, the Chinese speak Bahasa Indonesia (national Malay language in Indonesia) as fluently as indigenous Indonesians, and most of the younger Chinese can hardly speak Chinese. This is due to the smaller 
Chinese population having to interact with the indigenous Indonesians, as well as the assimilation policy of the authoritarian Suharto government (1966-1998), which banned Chinese schools and even Chinese writing. Compared to Chinese Indonesians, there are still some Chinese in Malaysia who do not speak Malay fluently, while there are some older ones who still speak poorly with heavy Chinese accent, described as pelat by the Malays and Malay-speaking Babas. This is mainly a result of the larger population of Chinese who use Malay only when they deal with Malays and with people who cannot speak Chinese or who cannot use English as a common language. Also, Chinese Malaysians have their own Chinese-medium primary schools and private secondary Chinese schools. Unlike in Indonesia, English is a common inter-ethnic language in Malaysia.

Elsewhere in Southeast Asia, where the Chinese populations are relatively small, we find that they speak the local languages very fluently, Thai in Thailand and Tagalog in the Philippines. In Iberian America, we find the Chinese speak Spanish. In dominant English-speaking societies, such as U.S.A. and Canada, English is the essential language that all migrants learn, so much so that it becomes the only fluent language of many migrants' descendants, speaking with American or Canadian accent. Thus, even when Chinese of different nationalities speak English, it is possible to detect their national origin. National education further fosters the linguistic acculturation of ethnic Chinese. The successful implementation of the national language policy in Malaysia no doubt contributes to the younger generation of Malaysians speaking Bahasa Malaysia fluently. Singapore adopts a different policy which emphasizes English, and the Singapore-style English (Singlish) is widely spoken even among children. Nevertheless, considerable effort has been placed on encouraging Chinese Singaporeans to learn or improve on their skill in Putonghua (Mandarin).

Related to language is the localization of personal names. This occurs in societies where Chinese are in small minority, and the adoption of Chinese names helps to ease acceptance by the local population. It can be also due to the wish on the part of the Chinese not to be seen as alien. Thus in Thailand, we find Chinese have Thai-sounding names or have both Chinese and Thai names. In Indonesia, however, the assimilation policy of the Suharto regime encouraged the Chinese to have Indonesian names. The need to be better accepted has encouraged most Chinese to adopt an Indonesian name. Some of them incorporate their original surname into the localized name while others use fully Indonesian name. In a visit to Jakarta, I was introduced to a Chinese who still spoke Mandarin. His Chinese name was Lin Zhengdong but he used his Indonesian name Harshah Witono. He explained that since the Indonesian name was meant for better acceptance by the indigenous Indonesians, it was better to use a full Indonesian name without any trace of his surname Lin, which in Hokkien is pronounced Lim.

In Christian majority countries, many Chinese adopt western/Christian personal names, although they generally retain their surnames. In Iberain South America, such name as Jose Tan (Tan being the Chinese surname) sounds very distinct to Chinese from non-Spanish speaking areas. Even the "English" transcription of Chinese surnames generally distinguishes the Chinese from Malaysia and Singapore from the Chinese elsewhere. In Malaysia, the Chinese transcribe their surnames according to their respective speech group and so most Chinese Malaysians can tell easily from the Romanized surnames which speech group another Chinese Malaysian belongs to. Thus, Chen (陈) in Putonghua is rendered as Tan in Hokkien, Tang in Teochew, Chan in Cantonese, Chin in Hakka, and Ting in Fuchow (Fuzhou). In Tahiti, most Chinese are of Hakka descent, and so the surname Chen is rendered as Chin or its variants like Tchen, Tchin, Tching, and Tsing, but also such other versions like Chene, Chene Taaitoa, Cheneson, etc. Indeed, the lack of standardized transcription and unique historical development had resulted in more than a hundred ways of rendering the surname Chen in Putonghua 
(Association Si Ni Tong Special Centenaire 1911-2011, 57), including variants of the Cantonese Chan, such as Chancet, Cansay, Chanseau, Chansin, Chansy, Chanzy, all of which most probably mean "Chan surname”. In Trinidad \& Tobago, the names of the localized Chines are quite distinct, bearing such surnames as Allum, Aquing, etc, perhaps due to the early migrants prefixing their personal name with "Ah" and the officers who registered migrants mistook the personal name as surname, hence Ah Lum became Allum, and Robert Allum, for instance, may be the full name of the descendants today. In Mauritius, the father's full name became the surname. For example, a local leader bears the name Chan Foon Kan Chan She Pi, Chan She Pi being his surname and this is the full name of his father. His family name is actually Chan.

Other common features of acculturation include dress-styles and architectural styles. In the Malay Archipelago, the more acculturated Chinese communities generally wear sarong and other indigenous people's style of dressing, making them distinct from the less acculturated ones. However, we need to see styles of dressing as fashion and today the nyonyas mostly wear other modern (so-called western-style) clothes. While Chinese may become acculturated, they generally build their temples in "traditional" Chinese style architecture, which projects the community's Chineseness. Some communities, such as those in Kelantan and Terengganu in Malaysia, however, have incorporated both Chinese and local architectural styles in building their houses. Thus, the Chinese in rural Terengganu and Kelantan have wooden houses built on stilt (thus of traditional Malay-style), but are still Chinese in symbolism and use of space (Tan, 1993, pp. 7-8). Nevertheless, the building of concrete modern houses is replacing these distinct local houses.

Of all the acculturated cultural features, other than language, food may be considered as another most innovative feature of cultural change. Chinese overseas acquire local taste, and so in matters of food, Chinese of different nationalities and regions generally have created distinct local cuisine. By incorporating local ingredients and styles of cooking, Chinese overseas have contributed to the invention of many new kinds of localized "Chinese food", which deserves more attention by scholars. In Malaysia and Singapore, the mainstream non-Baba Chinese have also created many kinds of local Chinese food, many of which are created out of inspiration from within the Chinese cuisine while others cater to the changing taste of the local Chinese, such as in the use of hot spices. Once acquired, the new taste has a lasting effect, as it influences one's perception of good taste. Although often neglected, the acculturation of foodways is, like language, an important and common experience of Chinese in localization, that is, in acquiring local cultural characteristics and consciousness. Indeed, language and food are the two cores localized cultural features experienced by the Chinese overseas.

Depending on the locale and time of settlement, there may be other aspects of cultural localization, in arts, literature, aesthetics, and others. Cultural localization refers to not only acculturation arising from people in direct interaction, but also other aspects of cultural change that is the result of local adaptation or invention out of the experience of migrants and their descendants living in a particular local environment. Chinese overseas all have features of cultural localization, some more than others. In addition, experience of living in a locale gives one a certain sentimental attachment and consciousness linked to that local living. Thus, Chinese of different nationalities generally show features of both cultural localization and local consciousness. All these influence the perception of identity, both the cultural expression of it (cultural identity) and the subjective ethnic consciousness of identifying as a particular kind of Chinese and with a nationality.

The cultural localization of the Babas is not as unique as it seems. In U.S.A., many highly local-born Chinese Americans are so acculturated that they not only speak only English but also know very little Chinese 
cultural traditions. From the narration of Louie (2004), Khu (2001), and others, it appears that to many such individuals, the historical connection to China provides an important sense of being Chinese as part of their American identity in the context of being treated by the larger society as "other", as Asians. There is thus an interest to visit the ancestral village or hometown of their parents or grandparents or earlier immigrant ancestors. The trip to their ancestral homeland is often experienced as a journal of identity discovery or negotiation of identities. Seeing the ancestral homeland and meeting relatives, albeit distant ones provide a concrete sense of historical rootedness and connectedness. The linguistic and cultural differences may make one feel more American, but in many cases, the encounter helps to reaffirm the Chinese part of their identity, or reconcile that one can be both Chinese and American without having to feel not sufficiently Chinese or American.

In Reunion Island which is situated 880 kilometers east of Madagascar, some of the highly acculturated and "racially" mixed people of Chinese descent remain connected to the historical memory of the China homeland, and today, there are not only people from Reunion Island who visit their ancestral homeland in China, but the well-off ones even sent their children to study in China, so as to be culturally more Chinese. We should not ignore the China factor, i.e.: the growing economic power has made more Chinese themselves feel the importance of learning Chinese, and there is also investment from China in Reunion Island (personal communication with Dr. Françoise Vergès, 19 June 2005, met in Cape Town, South Africa).

Unlike the highly localized Chinese in North America and in Reunion Island, the Babas do not have to relate to China to construct their Chinese identity. In my association with the Melaka and some Singaporean Babas, I do not find any rhetoric of China or imagery of the ancestral homeland in their construction of identity, even though they may describe their immigrant male ancestors as coming from China ${ }^{4}$, or they may be knowledgeable about Chinese popular fictions via Baba-style Malay translation. The Babas do not find the need to negotiate their identity by rediscovering their roots in China, for they observe Chinese festivals and practice Chinese rituals. Their Chineseness is rooted in these Chinese symbolism and rituals, although their identity is located in the Malay world.

Overall, migration to a new region and settlement results in localization and acquisition of new cultural identities. Even in imperial China, migration and localization had been taking place. Historically, the people of one region in China had migrated to other parts of the empire and so there were already diasporas within China, and the diasporic phenomenon was described in Chinese as liuyu, that is sojourning. After a few generations, these communities had little contact with the original homeland and became localized to the local society. In fact, Ping-ti Ho in his study of the associations (huiguan) in China noted from historical sources that the Hakka who migrated from Guangdong to Sichuan became tuzhuhua or "indigenized" and they all could speak more than one language (He, 1966, 111). Today the Sichuan Hakka in Luodai, for instance, still speak Hakka but identify themselves as Guangdongren or Guangdong people ${ }^{5}$. The Hakka had migrated within China and overseas. Today they are the most globally distributed Chinese and the descendants of the early migrants are all localized to the local societies in one way or another, whether in Southeast Asia, the Caribbean, India, Mauritius, or Tahiti ${ }^{6}$. In Indonesia, there are Hakka who have been so localized that they have incorporated a significant number of Indonesian words into their Hakka dialect, and when they re-migrated to China in 1961

\footnotetext{
${ }^{4}$ Song $(1923,69)$ mentions about Straits-born Chinese who had China-born fathers visiting China.

${ }^{5}$ This information is derived from my visit to Luodai on 8 July 2015 to meet up with my doctoral student, Li Sirui, who was doing her doctoral research there.

${ }^{6}$ For a recent study of the Chinese in Tahiti, see (Tremon, 2010).
} 
following the Indonesian ban on Chinese doing business in rural areas, they continued to speak this Indonesian-acculturated Hakka dialect, as I had observed in Yangshan of the Shuanyang Overseas Chinese Farm in Quanzhou, Fujian (Tan, 2010, 550).

\section{Discussion and Conclusion}

Cultural localization and acculturation involve cultural change as a result of individuals adapting culturally to a new multi-ethnic cultural environment and actively creating something new, in language, culinary style, arts, and so on, out of their experience of living for a long period of time in a locality. In the case of the Chinese overseas, their interaction with non-Chinese cultures provides a rich background for new cultural production. In an ethnically conscious society, this affects how the people view themselves and how others view them. We have seen that cultural traditions are relevant to this identification. The Malay-speaking Babas in Melaka hardly speak any Chinese, and they emphasize Chinese ancestor worship and the worship of Chinese deities, and they observe Chinese festivals religiously, except a minority of them who are Christians or followers of other faiths. All these practices provide the Babas a sense of being Chinese despite linguistic acculturation. In the case of those who do not speak any Chinese language and also have little knowledge of Chinese cultural traditions, there is a felt need to search for a more tangible root in a society where they still have to remain Chinese, or more broadly Asian, as we have seen in the case of Chinese Americans. Traditions thus become significant, not less, for identity politics, in the context of acculturation and globalization

As a result of cultural localization, Chinese overseas are becoming increasingly diverse even when they are at the same time homogenized by globalization. Such cultural changes, as in culinary borrowing and invention, should be celebrated, not ridiculed or despised from an imagined pure status, or despised as cultural degeneration from an essentialized view of Chinese culture. From the perspective of the extent of localization, we can identify three main categories of "acculturated" Chinese. Firstly, the Babas represent a category of localized Chinese who are linguistically acculturated, along with some other features of acculturation, but they continue to observe major Chinese traditions and Chinese symbolism. A product of localization, they look to their local past rather than to the ancestral Chinese homeland for their roots. Indeed, the Babas see Melaka as their ancestral homeland.

Secondly, there are people of Chinese origin, such as those in North America and Europe, who are so acculturated to the mainstream society that they hardly practice or know Chinese traditions. As we have seen, many of these eventually turn to China to search for ethnic origin and learn a bit about Chinese cultural heritage, in order to come to term with who they are ethnically and to better negotiate between ethnic and national identities. Scholars like Chan (1998) and Li $(1998,107)$ have observed that the second-generation Chinese generally try to acculturate themselves to the mainstream white society, thinking that in this way they can be fully accepted and treated the same. Their first-generation parents, however, tried but often without success, to socialize them to be culturally Chinese. The local-born Chinese Americans and Chinese Canadians grow up American and Canadian, but after they have graduated from school to work, they find that the imposed non-white Chinese identity is so strong that they are not treated by the mainstream society as the same. Chan $(1988,157)$ describes this experience of the second-generation Chinese Americans very well:

They were stunned to discover that the identity imposed on them as "Chinese" (or worse, as "Chinks" and "Chinamen”) was far more powerful, in terms of determining their "place” in American society, than whatever labels they might have fashioned for themselves. 
This experience is repeated by later generations of local-born Chinese. They are thus forced to retreat to their ethnic origin, hence the interest to search the Chinese roots, as described by Louie (2004).

Thirdly, there are those who are not only highly localized but also highly mixed "racially". This is a common feature in the Caribbean societies, but the best example of Chinese overseas in this category is that of the creolized Chinese of Reunion Island, who are creolized both culturally and biologically between Chinese, East Indians, Africans, and Europeans. Live (2004) identifies five groups of Chinese in Reunion. The first group comprises China-born immigrants and the second group is made up of the descendants of the first group, born before 1945. They remain culturally Chinese although the second group has more local features such as speaking Creole in addition to Chinese. The third group, born after the 1950s, is educated in French and is more localized, speaking Creole even to their parents. The fourth group comprises those born after 1975, who are more acculturated by the French. Interesting, some of these highly localized Chinese of the third and fourth groups, like the acculturated Chinese Americans, also try to get back to their Chinese roots. The fifth group is mixed in descent and a person with Chinese surname may look like a Creole, Malagasy, Tamil, or European (Live, 2004, 4). Some of them even try to rediscover their Chinese roots, including by visiting ancestral homeland in China.

Overall, Chinese overseas are diverse culturally and in identification. They may be all Chinese in one way or another, but they have different cultural expressions, hence the need to distinguish cultural identity and ethnic identification (Tan, 2004, 26). The label "Chinese" is imagined and perceived differently by different groups of Chinese. We have reviewed the concepts of acculturation, assimilation, hybridity, and creolization in relation to the Chinese overseas. All these concepts involve cultural formation in the context of cultural interaction between different ethnic categories of people. While American anthropologists have used the term “acculturation” for more than half a century (Bruner, 1956; Herskovits, 1958; Murphy, 1964; Padilla, 1980; Spiro, 1955), there is understandable concern that this may convey an image that people are passively acculturated to a dominant culture. In fact, as far back as the 1940s, Ortiz $(1947,97)$ had proposed the term "transculturation", which emphasizes exchange between cultures, as a substitute for the increasingly used term "acculturation", and Malinowski (1947) in the preface to the book endorsed it. If we bear in mind that acculturation is not passive adaptation to a standard culture and instead focus on cultural formation in a transcultural context, then the term "acculturation", despite the "unpleasant way it falls on the ear" (Malinowski (1947, p. viii), is still useful to distinguish it as a phenomenon in contrast to "assimilation”, as we have defined, and to indicate cultural change that makes a category of people increasingly culturally similar to the majority people in contact. The term "cultural localization" serves well to describe the cultural adaptation of migrants and their descendants to a new cultural environment. While migrants in-culturalize many aspects of new cultural experiences into their cultural life, thus reshaping or re-inventing cultural forms, in most circumstances they do have to acquire certain cultural features of the dominant cultural environment, especially language, that make them appear culturally similar to the mainstream society. Demographic, economic, and political factors in historical process bring about this phenomenon which can be easily understood as "acculturation", a form of cultural localization that emerges from unequal power relations.

Scholars writing about globalization prefer to use the terms "hybridity" and "creolization", in place of acculturation and assimilation. The attempt to emphasize the creative process of cultural formation in transcultural context is not new, as we have seen in the work of Ortiz (1947). However, it is often misleading to use hybridity and creolization interchangeably. I have explained the political and social implications of using 
the term "hybridity", to describe ethnic communities, but I argue that creolization may be used to refer to the kind of creative process of cultural formation in transcultural context, similar to the process of the formation of Creole arising from inter-linguistic contact. In the case of the Baba, we have seen that there is creolization of language and food. This specific usage of creolization, rather than branding the total cultural life of a people as creolized, except in a few specific historical contexts, is more useful for our analysis of such cultural process. While it is intellectually stimulating to universalize the concept of creolization to emphasize creativity and “richness of expression” rather than homogenization in global connectedness (Hannerz, 1996, 66), this explains very little when scholars assume all cultural forms as creolized. It is useful only when certain processes of cultural production can be identified as such, as I have proposed. Whatever it is, concepts have political and social implications, and scholars need to be responsible and sensitive to them. Nevertheless, in order to conveniently contrast the highly localized communities with a long history of settlement from latter migrants who are not so intensely acculturated, the term "creolized" may be used.

Scholars have increasingly used creolization to describe ethnogenesis and transformation arising from cultural contact (i.e., acculturation) beyond the Caribbean, such as the creolization in London, "the making Black of white British, and the making of white of Caribbean peoples” (Harney 1996, 112). This usage of creolization is similar to my wider usage of cultural localization of migrants and descendants. Nevertheless, we need to note that historically creolization as used in the Caribbean is acculturation largely in the direction of the colonial culture, unlike the case of the Babas or Chinese Peranakans in Southeast Asia, which is largely acculturation in the direction of the indigenous peoples. The Chinese who migrated to the Caribbean, Mauritius, and Reunion Island acculturate to the cultural life of the creolized African population. Intermarriage with the creolized Africans also makes the Chinese offspring physically very distinct, and to the extent that some of them still claim to be Chinese, they become a special category of "black Chinese". While in the early period of migration, some Chinese migrants in Southeast Asia and Hawaii, for instance, also intermarried with the local people, but over the years as they married Chinese migrants or local Chinese, they do not physically appear as significantly different from the other local Chinese, as in the case of the Babas.

The discussion on localization and identity helps us to understand migration and consequent processes of cultural transmission and cultural transformation as well as ethnic identification. The extent of cultural disruption following "voluntary" and forced migration determines the extent of retaining cultural traditions and acculturation or creolization, and all these affect their Chinesness and how they are perceived and how they perceive themselves. Despite the diversities of cultural formation, linguistic acculturation or assimilation is a common experience of the Chinese overseas. However, new waves of migration from China and the rise of China as a global economic power bring new impacts on the Chinese overseas everywhere, including encouraging and easing the learning of Putonghua, even though the children of these new migrants are themselves acculturating to the new societies.

\section{References}

Bhabha, H. K. (1994). The location of culture. London and New York: Routledge.

Brunner, E. (1956). Primary group experience and the processes of acculturation. American Anthropologist, 58(4), 605-623.

Chan, S. C. (1998). Race, ethnic culture, and gender in the construction of identities among second-generation Chinese Americans, 1880s to 1930s. In K. Scott Wong, \& S. C. Chan (Eds.), Claiming America: Constructing Chinese American identities during the exclusion era (pp. 127-164). Philadelphia: Temple University Press.

Chia, H. F. (2010). Phoenix rising: Narratives in Nyonya beadworks for the Straits Settlements. Singapore: NUS Press. 
Childs, P., \& Williams, R. J. P. (1997). An introduction to post-colonial theory. London and New York: Prentice Hall.

Chua, B. H., \& Ananda, R. (2001). Hybridity, Ethnicity and Food in Singapore. In D. Y. H. Wu, \& C. B. Tan (Eds.), Changing Chinese Foodways in Asia (pp. 161-197). Hong Kong: The Chinese University Press.

Clammer, J. R. (1980). Straits Chinese society. Singapore: Singapore University Press.

Eriksen, T. H. (1992). Us and them in modern societies: Ethnicity and nationalism in Trinidad, Mauritius and Beyond. Oslo: Scandinavian University Press.

Freyre, G. (1986). The masters and the slaves: A study in the development of Brazilian civilization. Translated from the Portuguese by Samuel Putnam, 2nd edition. Berkeley, Cal.: University of California Press. Original work published in 1933. First English translation published in 1946.

Hannerz, U. (1996). Transnational connections: Culture, people, places. London and New York: Routledge.

Harney, S. (1996). Nationalism and identity: Culture and the imagination in a Caribbean diaspora. Kingston, Jamaica: University of the West Indies Press.

He, B. D. (1966). Zhongguo huiguan shi lun (A historical survey of associations in China). Taipei: Taiwan Xuesheng Shuju.

Herskovits, M. J. (1958). Acculturation: The study of culture contact. Gloucester, Mass.: Peter Smith.

Hill, A. M. (1998). Merchants and migrants: Ethnicity and trade among Yunnanese Chinese in Southeast Asia. New Haven, Con.: Yale University Southeast Asia Studies.

Hoetink, H. (1973). Slavery and race relations in the Americas: An inquiry into their nature and nexus. New York: Harper Torchbooks.

Jenkins, R. (1997). Rethinking ethnicity: Arguments and explorations. London: Sage Publications.

Khu, J. M. T. (2001). Cultural curiosity: Thirteen stories about the search for Chinese roots. Berkeley: University of California Press.

Li, P. (1998). Chinese in Canada (2nd ed.). Toronto: Oxford University Press.

Liang, L. J. (1996). Hubungan empayar Melaka-Dinasti Ming abad ke-15 (Relations between Melaka Empire and the Ming Dynasty in the 15th century). Bangi: Penerbit University Kebangsaan Malaysia (In Malay).

Live, Y.-S. (2004). Illusory identities and cultural "métissage” among the "Sinoi” on Reunion Island. ISSCO V International Conference-New Chinese Migrants: Globalization of Chinese Overseas Migration. Organized by the Department of Asian Studies and the Nordic Institute of Asian Studies, University of Copenhagen, Elsinore, Denmark, May 10-14, 2004.

Louie, A. (2004). Chineseness across borders: Renegotiating Chinese identities in China and the United States. Durham: Duke University Press.

Malinowski, B. (1947). Introduction. In Ortiz (1947).

Menke, J., \& França, M. S. D. C. (2005). "Racial mixing” in Latin America and the Carribean: The case of Brizil and Surinam. Mixing Races. Organized by the Sephis Programme and the University of Cape Town, South Africa, 16-21 June 2005.

Mintz, S. W. (1996). Enduring substances, trying theories: The Caribbean region as oikoumenê. The Journal of the Royal Anthropological Institute, 2(2) (N.S.), 289-311.

Mintz, S. W. (1998). The localization of anthropological practice: From area studies to transnationalism. Critique of Anthropology, 18(2), 117-133.

Murphy, R. F. (1964). Social change and acculturation. Transactions of the New York Academy of Sciences, (Ser. II) 26(7), 845-854.

Ortiz, F. (1947). Cuban counterpoint: Tobacco and sugar. New York: Alfred A. Knopf, Inc. Reprint by Duke University Press, 1995.

Padilla, A. M. (1980). Acculturation: Theory, models and some new findings. Washington, D.C.: American Association for the Advancement of Science

Rudolph, J. (1998). Reconstructing identities: A social history of the Babas in Singapore. Aldershot, England: Ashgate.

Scheller, M. (2003). Creolization in discourses of global culture. In Sara Ahmed, et al. (Eds.), Uprooting/regroupings: Questions of home and migration (pp. 273-294). Oxford and New York: Berg.

Shibata, Y. (2013). Changing identities of the Chinese in the Anglophone Caribbean: A focus in the Anglophone Caribbean. In T. Chee-Beng (Ed.), Routledge handbook of the Chinese diaspora (pp. 359-374). London: Routledge.

Skinner, G. W. (1957). Chinese society in Thailand: An analytical history. Ithaca, NY: Cornell University Press.

Skinner, G. W. (1960). Change and persistence in Chinese culture overseas: A comparison of Thailand and Java. Journal of the South Seas Society, 16(1\&2), 86-100. 
Skinner, G. W. (1996). Creolized Chinese societies in Southeast Asia. In Anthony Reid (Ed.), Sojourners and settlers: Histories of Southeast Asia and the Chinese (pp. 51-93). Australia: Allen \& Unwin.

Song, O. S. (1923). One hundred years' history of the Chinese in Singapore. London: John Murray. Reprinted in 1967 by University of Malaya Press, Singapore, and in 1984 by Oxford University Press, Singapore.

Spiro, M. E. (1955). The acculturation of American ethnic groups. American Anthropologists, 57(6), 1240-1252.

Tan, C. B. (1988). The Baba of Melaka: Culture and identity of a Chinese Peranakan community in Malaysia. Petaling Jaya (Malaysia): Pelanduk Publications.

Tan, C. B. (1993). Chinese Peranakan Heritage in Malaysia and Singapore. Kuala Lumpur: Fajar Bakti.

Tan, C. B. (1994). Communal associations of the indigenous communities of Sarawak: A study of ethnicity and national integration. Kuala Lumpur: Institute of Advanced Studies, University of Malaya.

Tan, C. B. (2001). Food and ethnicity with reference to the Chinese in Malaysia. In D. Y. H. Wu, \& C. B. Tan (Eds.), Changing Chinese foodways in Asia (pp. 125-160). Hong Kong: The Chinese University Press.

Tan, C. B. (2004). Chinese overseas: Comparative cultural issues. Hong Kong: Hong Kong University Press.

Tan, C. B. (2010). Reterritorization of a Balinese Chinese community in Quanzhou, Fujian. Modern Asian Studies, 44(3), 547-566.

Teske, R. H. C., Jr., \& Nelson, B. H. (1974). Acculturation and assimilation: A clarification. American Ethnologist, 1(2), $351-367$.

Tong, C. K., \& Chan, K. B. (2001). Alternate identities: The Chinese of contemporary Thailand. Singapore: Times Academic Press.

Trémon, A. C. (2010). Chinois en Polynésie française: Migration, mêtissage, diaspora. Nanterre: Société d’ethnologie.

Van Lier, R. (1971). Frontier society: A social history of the Suriname. The Hague: Martinus Nijhoff. Translation of the author's doctoral thesis, 1949.

Wickberg, E. (1964). The Chinese Mestizo in Philippine history. Journal of Southeast Asian History, 5(1), 62-100.

Wong, B. (1978). A comparative study of the assimilation of the Chinese in New York City and Lima, Peru. Comparative Studies in Society and History, 20(3), 335-358. 